\title{
A CONSTRUÇÃO DISCURSIVA DE NARRATIVAS COLETIVAS DA IDENTIDADE NACIONAL PORTUGUESA: HOMOGENEIDADE OU DIVERSIDADE?
}

\author{
Filipa Perdigão Ribeiro
}

\begin{abstract}
RESUMO
As conceções dominantes do Portugal "autêntico" ou "real" estão agora tão naturalizadas no discurso nacional que muitos dos contextos socio-históricos da sua construção discursiva foram apagados da memória coletiva das pessoas. Este artigo apresenta uma visão geral das narrativas e memórias coletivas mais proeminentes no contexto português, destacando os eventos históricos que as moldaram, como por exemplo a Revolução de 1974, a partir da qual todas as narrativas atuais sobre identidade nacional construíram as suas principais referências. Este texto refere brevemente a historiografia do século XIX, a conceptualização do Estado Novo sobre a "missão nas colónias" de Portugal, a rutura ideológica da Revolução com o antigo regime e os principais mitos de homogeneidade e estereótipos. Deste modo, os discursos contemporâneos sobre a identidade nacional portuguesa são considerados à luz da memória social e da mudança diacrónica.
\end{abstract}

Palavras-chave

Identidade nacional portuguesa; narrativas coletivas; discursos; Revolução de 1974; nacionalismo banal

\section{THE DISCURSIVE CONSTRUCTION OF COLLECTIVE NARRATIVES ON PORTUguese National IDENTITY: HOMOGENEITY OR DIVERSITY?}

\begin{abstract}
Mainstream conceptions of the "authentic" or "real" Portugal are now so naturalized in national discourse that many of the socio-historical contexts of their discursive construction have been erased from people's collective memory (-ies). This paper presents an overview of the prominent collective narratives and memories in the Portuguese context, highlighting salient historical events that shaped them, such as the 1974 revolution which was a watershed moment from which all current narratives on national identity construct their major reference. It briefly covers 19th century historiography, the Estado Novo's concept of Portugal's "mission in the colonies", the revolution's ideological break with the old regime, and the major myths of homogeneity and self-stereotyping. Thus, contemporary discourses on Portuguese national identity are considered in the light of social memory and diachronic change.
\end{abstract}

KEYWORDS

Portuguese national identity; collective narratives; discourses; 1974 revolution; banal nationalism 


\section{INTRODUÇÃo}

Portugal, através do Museu Nacional de Arte Antiga, apresenta a todos os visitantes, nacionais e internacionais, o melhor da produção cultural que demonstra, uma vez mais, o seu papel como produtor e produto de boas práticas de comunicação global, sua matricial vocação identitária, através dos registos históricos de natureza científica, artística, cultural e comercial. Este movimento cumpriu-se da Europa para o Mundo e deste para a Europa, para onde os portugueses sempre trouxeram, entre o século XV e a atualidade, essa riqueza primordial que é a imensa diversidade humana.

Este excerto, retirado do texto introdutório da exposição internacional Englobando o globo: Portugal e o mundo, nos séculos XVI e XVII (16 de julho a 11 de outubro de 2009, Museu Nacional de Arte Antiga), incorpora alguns dos principais temas da identidade nacional portuguesa contemporânea: a nação "pioneira dos mares" como mediadora entre "nós, os europeus" e "eles, o resto do mundo"; a nação como guardiã da "diversidade humana", ou, em termos modernos, do "multiculturalismo e tolerância"; a nação como mediadora que "ofereceu novos mundos ao mundo". O texto encapsula a proeminência de uma narrativa hegemónica profunda de identidade cultural, histórica e essencialista que permeia a maior parte do discurso sobre a identidade nacional portuguesa'. Sob essa perspetiva, somos levados a perguntar como é que esses mitos de homogeneidade surgiram, uma vez que posições nacionalistas são facilmente descartadas como algo extremista e irracional (Billig, 1995). A tentação de situar o discurso nacionalista entre o tipo de vocabulário que "nós", os cidadãos instruídos, não usamos é grande. No entanto, num artigo de opinião publicado em 26 de março de 2008 , o poeta e político português Manuel Alegre declarou, em relação ao Acordo Ortográfico de 1990: "o que está em jogo é uma questão de identidade nacional". Ainda neste contexto, o Acordo foi descrito, entre outras coisas, como "um ataque à nossa língua", "um desrespeito pela diversidade e riqueza linguística" e "um erro histórico" (Carita, 2008, p. 16). Aliás, entre as gerações mais jovens, as opiniões não diferem. Os resultados de um inquérito aplicado a 198 estudantes universitários revelou que 70,7\% rejeitaram o Acordo para "proteger a identidade cultural portuguesa e preservar o património cultural do papel de liderança de Portugal durante o período do império" (Carvalho \& Cabecinhas, 2013, p. 88). Estes dois exemplos ilustram como a questão da identidade nacional emerge na vida pública portuguesa com regularidade, quer seja com base em razões políticas, económicas e sociais, ou, neste caso, linguísticas.

De entre as principais teorias que dizem respeito à "criação da nação", o foco deste trabalho são os séculos XIX e XX, quando a maioria dos debates questionando a identidade nacional ganha destaque, salientando as grandes tensões e revoltas que Portugal

\footnotetext{
' Outro exemplo recente desta narrativa essencialista da identidade é o Discurso da Tomada de Posse do atual presidente português, Marcelo Rebelo de Sousa, no qual declarou: "Os valores matriciais da Constituição são igualmente os da identidade nacional, enraizados na nossa terra e no nosso mar, mas de vocação universal - uma plataforma que construímos entre continentes e, sobretudo, entre culturas e civilizações". Discurso da Tomada de Posse do Presidente da República, Marcelo Rebelo de Sousa no Parlamento, 9 de março de 2016, retirado de http://www.presidencia.pt/?idc=22\&idi=103410
} 
tem enfrentado ao lidar com o "outro". Além disso, nas últimas décadas, Portugal tem estado sujeito a vários processos históricos e sociais. Em abril de 2004, a Revolução comemorou o seu $30 .^{\circ}$ aniversário e uma série de académicos e formadores de opinião estavam finalmente em condições para iniciar o debate sobre o passado recente das últimas três décadas. A Revolução havia acabado com o domínio político de Portugal sobre as suas antigas colónias africanas e havia dado novo alento ao longo debate sobre o "papel simbólico de Portugal" e sobre a interpretação mítica de sua identidade nacional. A adesão à União Europeia em 1986 e a crescente globalização económica levaram à urgente reflexão sobre as consequências da Revolução e também sobre o debate em curso centrado na identidade nacional. Além disso, o número crescente de migrantes económicos que chegaram a Portugal a partir dos anos $80^{2}$ colocou inevitavelmente em questão a ideia de "cidadãos perfeitamente assimilados" e forçou repensar na reformulação das instituições nacionais e dos direitos relacionados com os grupos, com implicações para a natureza e práticas da identidade nacional (Biles \& Spoonley, 2007, p. 194). Curiosamente, a construção e consolidação da nação portuguesa remonta historicamente ao século XIII, e apresenta alguns traços desviantes em relação a algumas das principais teorias que atribuem a criação do nacionalismo ao Estado moderno (Anderson 1983/2006; Gellner 1983/2006; ver também Almeida, 2004, sobre a situação distinta de Portugal).

Aqui a análise é guiada por quatro fatores principais que moldaram a construção discursiva da identidade nacional de Portugal. Primeiro, enquanto país pequeno e modestamente povoado, a relação com uma Espanha avassaladora e única vizinha moldou a maioria dos debates sobre o tema ${ }^{3}$. O segundo fator relaciona-se com o conceito de "glorioso império ultramarino", cuja administração foi empreendida pelo Estado português desde o início do século XV até meados do século XX4. Por sua vez, essas relações "imaginárias" "imaginadas" e reais no exterior moldaram a perceção do país sobre a sua relação com a Europa, percebida e (discursivamente) construída como um todo integral e abstrato (ou seja, os países não são entidades únicas e individualizadas). A ditadura e a guerra colonial em África (que durou treze anos), ambas durante o século $\mathrm{XX}$, constituem os fatores número três e número quarto com impacto decisivo na autoimagem de Portugal nos discursos públicos e nas narrativas de autorrepresentação. Esses fatores serão explorados nas secções abaixo.

Com base nestes pressupostos, este artigo discute as narrativas coletivas e memórias salientes no contexto português, ligando-as aos acontecimentos históricos que as moldaram. Foi estruturado de forma a fornecer uma visão geral, mas concisa, de algumas das dimensões sociopolíticas e históricas em Portugal relacionadas com questões

\footnotetext{
${ }^{2}$ Ver Vieira e Trindade (2008) e Peixoto (2014) para uma perspetiva global dos recentes fluxos migratórios para Portugal.

${ }^{3}$ Já no século XIV, a população portuguesa sentia um crescente sentimento de ódio contra Castela e Leão (dois dos vários antigos reinos que vieram a transformar-se na Espanha). Vários autores, entre os quais Saraiva e Lopes (1987), mostraram como esses sentimentos levaram a investidas regulares ao longo dos séculos, nos momentos em que a independência de Portugal estava em jogo.

${ }_{4}$ O poder administrativo da nação estendia-se desde Portugal até à Índia (Goa, Damão e Diu), China (Macau), Ásia Oriental (Timor Leste), África (Moçambique, Angola, Guiné-Bissau, Cabo Verde e S. Tomé e Príncipe) e América Latina (Brasil).
} 
de construção de identidade e de "pertença" de um ponto de vista macro, a partir da exploração de estudos críticos do discurso, de história, de sociologia e de antropologia. O objetivo é traçar a construção do discurso público sobre a identidade nacional que enquadra os discursos contemporâneos nacionais sobre esta temática e compreender de que forma as autoridades estatais e as elites académicas e políticas, através da mediação da esfera pública - média, escola, discurso público, narrativas históricas, etc. -, têm desempenhado um papel fundamental na formação das memórias e narrativas coletivas recentes.

Na próxima secção descrevem-se as principais narrativas na historiografia do século XIX, altura em que os primeiros debates públicos sobre a questão da "identidade nacional" emergem. Em segundo lugar, serão descritas as narrativas mais proeminentes da "missão de Portugal no mundo" impostas à população durante a época da ditadura. A guerra colonial, que decorreu nos últimos treze anos do Estado Novo, e o seu papel fundamental na construção das narrativas nacionais de identidade, também são abordados. Em terceiro lugar, focar-se-á a forma como a Revolução do 25 de abril de 1974 e as suas consequências moldaram as narrativas e as memórias coletivas no passado recente e como as elites de Portugal sentiram uma forte necessidade de "repensar Portugal", retomando o antigo debate do século XIX. Defendido por muitos escritores e historiadores, este debate favoreceu o projeto europeu em detrimento do "projeto imperial". Segue-se um resumo das principais reivindicações sobre as narrativas dominantes da identidade nacional portuguesa, conforme são apresentadas por historiadores, sociólogos, filósofos e escritores, e como esses discursos constroem "o outro". A secção final aborda as representações discursivas do relacionamento de Portugal com três atores específicos: Espanha, Europa e os novos migrantes.

\section{PRESSUPOSTOS SUbJACENTES À CONSTRUÇÃo DisCURSIVA DE NAÇõES E IDENTIDADES NACIONAIS}

O entendimento de identidade nacional e de nacionalidade que aqui se segue baseia-se em diversos sobrepostos. Para começar, as nações devem ser entendidas como construções mentais, como "comunidades políticas imaginadas" (Anderson, 1983/2006, p. 6). "Estão representados nas mentes e memórias dos nacionais como unidades políticas soberanas e delimitadas" (De Cillia, Reisigl \& Wodak, 1999, p. 153), através de discursos (linguagem e outros sistemas semióticos) produzidos, reproduzidos, transformados e/ou destruídos. O ditador português António de Oliveira Salazar compreendia claramente como esta representação funcionava e aplicou-a ao império colonial português. Atualmente, esta representação ainda desempenha um papel importante na construção discursiva da identidade nacional portuguesa. Em segundo lugar, a identidade nacional pode ser considerada como uma espécie de "habitus" (partindo do conceito de Bourdieu), ou seja, "um complexo de ideias comuns, conceitos ou esquemas de perceção comuns de atitudes emocionais intersubjetivamente partilhadas por um grupo específico de pessoas, as quais são todas interiorizadas através da socialização nacional" (De Cillia et al., 1999, p. 153). 
No caso da nação portuguesa, as ideias, conceitos ou questão dizem respeito à ideia de traços específicos do caráter de ser português que distinguem os portugueses dos outros povos - incluindo noções estereotipadas que "nos" distinguem de "eles", nomeadamente uma "história nacional comum, cultura, presente e futuro", bem como um "território nacional específico". Estas disposições comportamentais incluem a solidariedade com o próprio grupo nacional, bem como a exclusão dos "outros" deste coletivo construído.

O próximo pressuposto, que se interliga com o anterior, diz respeito às ligações muito estreitas entre "construção discursiva de nações e de identidades nacionais" e "a construção de diferença/distintividade e singularidade" (De Cillia et al., 1999, p. 153). No momento em que é "elevado ao nível do imaginário coletivo", tanto a construção daquilo que é semelhante como a construção daquilo que é diferente violam a variedade plural e democrática e a multiplicidade, dada a pressão interna do grupo no sentido da homogeneização" (De Cillia et al., 1999, p. 153). Este último argumento é visível na persistente tentativa de homogeneização do grupo interno transmitida nos media ou, por exemplo, nos discursos presidenciais 5 . Mesmo assim, a identidade nacional nunca é fixa num sentido essencialista, já que existirão sempre, invariavelmente, conceções, histórias e estereótipos em concorrência (Billig, 2009, p. 348). Também identidades diferentes são discursivamente construídas de acordo com o contexto, nomeadamente, o público alvo dessas narrativas, o cenário situacional do ato discursivo e o tema em discussão (De Cillia et al., 1999, p. 153; Wodak, 2006, p. 106). Por fim, a vida contemporânea é diariamente injetada com pressupostos e símbolos nacionalistas, que muitas vezes passam despercebidos. Isto é, "o complexo de crenças, suposições, hábitos, representações e práticas" é reproduzido endemicamente de forma "banalmente mundana" (Billig, 1995, p. 6).

\section{RAÇA E NACIONALIDADE}

Portugal é o estado-nação mais antigo da Europa, com fronteiras a datar do século XII, quando o aspirante a rei, Afonso Henriques, batalhou contra o seu próprio primo, Alfonso VII do Reino de Leão. Afonso Henriques acabou por se coroar rex Portugalensis (Rei de Portugal) e adotou uma política expansionista contra os mouros e os espanhóis. Esta narrativa fundadora do país é bem conhecida dos portugueses. Relembramo-la aqui pelo seu valor paradigmático em termos da visão essencialista da identidade nacional portuguesa consensualmente aceite. Para implementar essa visão, o Estado Novo controlou o currículo do ensino da História, impondo narrativas oficiais e valorizando a relação entre a história e os projetos nacionalistas, nomeadamente as versões românticas da nação criadas durante o século XIX (Torgal, 1989). Na verdade, essas versões românticas - originalmente moldadas pela historiografia do século XIX - da narrativa fundadora vieram apresentar uma separação definitiva do que seria mais tarde a Espanha e têm sido utilizadas discursivamente para distanciar Portugal do seu vizinho territorial.

\footnotetext{
${ }^{5}$ Ver a nota de rodapé $n .^{\circ} 1$.
} 
Durante o século XIX, tal como por toda a Europa, as questões do nacionalismo dominaram a esfera pública portuguesa. As teorias que explicavam a génese da nação faziam parte da cultura geral (Sobral, 2004, p. 257). O historiador Alexandre Herculano (1846/1980-81) argumentou que a nação portuguesa era um produto político, resultado da sua formação nas mãos dos barões da parte noroeste da Península Ibérica. Outro proeminente historiador do século XIX, Oliveira Martins (1879), na sequência das ideias de Herculano, acrescentou que existiam traços de origem celta no caráter português. Oliveira Martins (1879, p. 29) acreditava numa civilização ibérica, num "caráter peninsular [que consistia] no traço fundamental da raça". Assim, o argumento étnico/racial acabou por ser difundido durante as décadas de 1870 e 1880. A representação da história do país, em paralelo com a de Espanha, era composta por duas etapas principais: uma de grandeza, que atingiu o seu pico durante os impérios marítimos do século XVI; e a seguinte, de decadência, que durou até o século XIX. Teófilo Braga, também um historiador português, insistiu na abordagem étnica para explicar a nacionalidade portuguesa, defendendo até que havia uma distinção racial dos espanhóis, incluindo a influência árabe durante os sete séculos de domínio dos mouros nas regiões do sul de Portugal (Braga, 1885, 1894).

Como resultado, o fator racial foi percebido como um elemento proeminente na organização social. Na segunda metade do século XIX, a interpretação do nacionalismo com fundamento na raça (mesmo que fosse uma combinação de diversos povos) contribuiu para um sentido de comunidade, baseado na falsa sensação de uma origem única e de um destino comum. Durante este período, e estendendo-se até às primeiras décadas do século $X X$, sucessivas crises políticas e económicas, o cada vez menor papel político do país na Europa, e a crescente migração da população para o Brasil, incutiram a ideia de que "a essência histórica dos primeiros séculos do estado português" (Sobral, 2004, p. 266) tinham de voltar a ser capturados.

Numa fase ulterior, alegando a presença de traços de caráter comuns, outros autores sugeriram que existia uma continuidade ou homogeneidade entre os povos lusitanos e o português (Correia, 1919), ou até entre vários grupos étnicos, incluindo árabes, judeus e africanos subsarianos (Vasconcellos, 1940-1941). Após a Segunda Guerra Mundial, os currículos escolares, apesar de terem incorporadas a ideologia fascista de António de Oliveira Salazar, davam ênfase à multiplicidade de contribuições étnicas para - povoamento da Península Ibérica, nunca mencionando palavras como "Ariano" ou "semita" por causa da sua óbvia estigmatização. Sob a ideologia nacionalista de Salazar, a ênfase colocada nas múltiplas origens étnicas do povo lusitano foi expandida através do conceito de lusotropicalismo de Gilberto Freyre "que incorporava o mito de um harmonioso Império Português multirracial" (Cusack, 2005, p. 601). Como tal, os portugueses "tinham um fim ou propósito didático: o de desvalorizar quanta tese racista se levanta contra os povos heterogéneos. Nunca o ideal de pureza de raça animou ou limitou os esforços portugueses" (Freyre, 1942, p. 48) ${ }^{6}$. Este conceito, apropriado pela

\footnotetext{
${ }^{6}$ A conceptualização inicial do conceito "lusotropicalismo" foi introduzida pela primeira vez pelo antropólogo brasileiro Gilberto Freyre na obra Casa-Grande Q Senzala (1933). As expressões "luso-tropical" e "tropicalismo" são formuladas pela primeira vez nas conferências que o autor profere em Goa (1951) e em Coimbra (1952) e mais tarde reunidas na obra Um brasileiro em terras portuguesas (1953) do mesmo autor (Castelo, 1999, p. 33, 2011, p. 267). O conceito engloba o
} 
ideologia salazarista - porque fornecia o repertório para o regime responder às críticas cada vez mais fortes das Nações Unidas e de outros foros internacionais (Sidaway \& Power, 2005) - propunha que

\begin{abstract}
a independência do português se processou pela negação de qualquer puritanismo étnico (...) e por uma 'consciência de espécie' não biológica, de semelhanças rigorosamente de raça, mas social: a consciência de necessidades, de aspirações, de interesses comuns entre elementos etnicamente heterogéneos. (Freyre, 1942, p. 25)
\end{abstract}

Embora modernizada, esta imagem multicultural dos portugueses prevalece em termos de construção discursiva.

\title{
O Estado Novo E A PORTUgaliddade
}

O ditador de direita António de Oliveira Salazar chega ao poder político como ministro das Finanças em 1928 e inicia o Estado Novo, oficializado na Constituição de 1933. Enquanto primeiro-ministro, Salazar acabou por governar o país praticamente sozinho de 1932 a 1968. O regime ditatorial durou até à revolução de 25 de Abril de 1974, na altura já sob o comando do único outro primeiro-ministro do Estado Novo, Marcello Caetano, que sucedeu a Salazar em 1968. Em 1974, Portugal possuía o regime fascista mais antigo do mundo. Lamentavelmente, o governo de Salazar/Caetano tinha subsistido ao período entre as Grandes Guerras, à Segunda Guerra Mundial, e ao período do pós-guerra e imposto valores nacionalistas à população portuguesa. Entretanto, o sistema de ensino fora adaptado de forma a glorificar a nação portuguesa e os seus territórios ultramarinos centenários.

A partir dos anos 1930, o Estado Novo assume a "função histórica de possuir e colonizar domínios ultramarinos e de civilizar as populações indígenas que neles se compreendam" (Ato Colonial, 1930, artigo 2). Esta seria a missão e "o fardo do homem português" (Rosas. 2001, p. 1034) e a essência orgânica da nação portuguesa que, por sua vez, justificava e legitimava o direito de ocupar, possuir e colonizar os territórios ultramarinos. Estes direitos alienáveis sobre os territórios ultramarinos estavam fundamentados na manutenção da independência nacional, percebida e discursivamente construída como estando constantemente sob ameaça de Espanha. Ao mesmo tempo, a grande dimensão do Império Colonial compensava o tamanho do pequeno Portugal continental (Rosas, 2001).

$\mathrm{Na}$ busca de seus objetivos, o Estado Novo tentou estabelecer uma ideia mítica da "essência portuguesa" (Rosas, 2001, p. 1034). Salazar estava, no entanto, preocupado principalmente com as elites, pois acreditava que o futuro da nação e do regime dependia, sobretudo, das elites instruídas, que perpetuariam o "verdadeiro interesse nacional" (Rosas, 2001, p. 1038).

conhecimento experiencial vivo e direto dos trópicos, tanto no Oriente como em África ou na América, que deu lugar a um novo tipo de civilização lusotropical, implicando um caráter simbiótico único de união entre a Europa e os trópicos. 
Sendo este o caso, o domínio forte da ditadura fora construído sobre uma ideologia que propunha o conceito de Portugalidade e o expansionismo ultramarino, bem como a ideia de família e da religião católica. Portanto, "perder África" na década de 1970, a última posse política e simbólica do império ultramarino, era (e ainda é para alguns setores da população) a grande perda de uma nação que permaneceu incapaz de encontrar-se (Ferreira, 1993 p. 173). Muitos portugueses encaravam os territórios ultramarinos e Portugal como eternamente ligados através da língua e cultura portuguesas`. No entanto, exceto para o setor religioso (cujo suporte era a estrutura da Igreja), a abordagem autoritária piramidal para a divulgação destas ideologias nunca teve o efeito de imbuir totalmente as pessoas na "sinalização-da-nação" (flagging-of-the-nation) (Billig, 1995). $\mathrm{Na}$ verdade, largos setores da população ressentiam-se cada vez mais das colónias e, a partir de 1961, quando a guerra colonial começou em Angola, do esforço de guerra. Este último envolveu uma drenagem significativa no orçamento nacional e, mais importante, exigiu um elevado número de jovens recrutas masculinos ${ }^{8}$. Outro fator de ressentimento em relação às colónias africanas era a implicação de uma "portugalidade danificada" produzida pelos portugueses que haviam emigrado para África. Percebeu-se que esses migrantes rotulados de "retornados" mantinham um estilo de vida e "práticas que eram consideradas moralmente suspeitas por parentes e membros da comunidade que haviam permanecido para trás em Portugal" (Lubkemann, 2002, p. 189). Como resultado, após a Revolução de 1974, os chamados retornados foram fortemente estigmatizados pela população que permaneceu em Portugal ${ }^{9}$, em forte contraste com os portugueses que tinham migrado para outros destinos, como a França, o Luxemburgo ou a Alemanha ou ainda o continente Americano (Lubkemann, 2002).

Deste modo, o Estado Novo reivindicou e divulgou a imagem de um "Portugal maior", uma representação necessária para defender a independência de Portugal contra "o outro". A população em geral, na sua maioria analfabeta, assimilava estas representações ao mesmo tempo que se ressentia da nação de facto por razões económicas, sociais e emocionais, já que "os seus rapazes" tinham que navegar para o ultramar para lutar nas guerras coloniais. Paralelamente, pequenas minorias das elites instruídas sustentavam a ideologia do Estado ou revoltavam-se contra ela - na medida do possível, dada a censura e o papel ativo da polícia política, conhecida pelo acrónimo PIDE - questionando a dita "missão" portuguesa nas colónias. Esta ambivalência relativamente à ideia hegemónica da nação persistiria durante os anos imediatamente após a Revolução, e ainda mais no futuro, moldando os discursos sobre a identidade nacional e a rejeição inicial de tudo o que estivesse relacionado com patriotismo ou com símbolos nacionais, uma vez que estes eram vistos como autoritários, antidemocráticos e contra a liberdade ${ }^{10}$.

\footnotetext{
7 Num estudo de 2001, os portugueses admitiram as quatro principais razões para se sentirem orgulhosos do país: os Descobrimentos, a Revolução do 25 de abril, a língua portuguesa por todo o mundo e os laços históricos com outros povos (Almeida, 2004).

${ }^{8}$ Calcula-se que um milhão de pessoas tenha estado envolvido (incluindo civis, famílias, etc.) no esforço de guerra, viajando para África a determinada altura durante no período de 1961-1974.

9 Ver, a título de exemplo, o post em blogue de Passos (2016, 6 de janeiro) no qual ele descreve essa experiência traumática.

10 De facto, a população em geral parece ter feito as pazes com a bandeira portuguesa durante a Expo em 1998 e, posteriormente, durante o Campeonato Europeu de Futebol em 2004, eventos nos quais a bandeira foi orgulhosamente exibida.
} 


\section{O 25 de Abril e a (BREVE) RejeiçÃo dos Símbolos naCionais}

A Revolução introduziu uma rutura importante com os valores autoritários, as crenças e as ideologias do regime anterior (Barreto, 1995, 2000; Cabral, 1999). Durante o inevitável entusiasmo pós-revolucionário, a população portuguesa sentiu que os paradigmas culturais impostos anteriormente se tinham desmoronado, nomeadamente a insistência em manter a esfera privada "secreta" e a esfera pública" sob o escrutínio da censura, uma vez que no período pós-revolução, as ideologias sociais predominantes promoviam o coletivo sobre o indivíduo. Almeida (2004, p. 3), por exemplo, sugere que, em termos de memória coletiva, a "revolução inaugurou a maior utopia coletiva dos portugueses". No entanto, acrescenta o autor, durante a turbulência as pessoas esqueceram-se de que o passado é componente da identidade nacional. De facto, por um breve período, o Portugal pós-revolucionário tentou rejeitar o seu passado recente e, associada a essa rejeição, a sua história coletiva, precisamente porque a política ideológica do Estado Novo havia apropriado, reenquadrado e incorporado essa mesma história coletiva.

A essa breve interrupção dos discursos públicos dominantes/hegemónicos seguiu-se, na década de 1980, uma crescente desconfiança nas ideologias sociais defendidas pelos partidos de esquerda. O enfoque político na cultura enquanto património, na portugalidade e na identidade nacional retornaram. Ser "nacional" torna-se um valor unificador na preocupação crescente sobre a imagem do país e sobre o seu reconhecimento na Europa, juntamente com a falta de debate sobre o que seria relevante em termos de políticas culturais (Reis, 1993, p. 473).

A partir de uma perspetiva analítica, durante os anos oitenta e noventa, académicos portugueses sentiram a necessidade de revisitar o passado histórico com base em premissas científicas modernas e válidas. Os investigadores estavam interessados em interpretar a identidade de Portugal (e a política) à luz de cenários internacionais: Europa, Estados Unidos, relações internacionais Norte-Sul e as antigas colónias portuguesas em África. Os investigadores tornaram-se cada vez mais conscientes de que, para compreenderem Portugal, tinham de olhar para o "outro" (Barreto, 1994, p. 1064). Desde então, os sociólogos têm argumentado que fenómenos considerados de tipo permanente pelo Estado Novo, e até certo ponto ainda enraizados nos discursos coletivos sobre a identidade nacional, estão, na verdade, em constante mutação. Exemplos destes seriam a cultura, a língua, a etnia, a religião e certas tradições portuguesas (Barreto, 2000, p. 38).

\footnotetext{
Em 2000, com o objetivo de aumentar a consciência nacional, o governo português distribuiu o chamado kit patriótico a crianças do ensino básico e incentivou as crianças a cantarem o hino nacional (Almeida, 2004).

"De acordo com o modelo tradicional de Jürgen Habermas (1962/1989), o elemento mediador do sistema social é a esfera pública, compreendendo as principais instituições políticas e culturais e a imprensa. Os agentes sociais ou reproduzem ou contestam a estrutura institucional, permitindo assim um potencial de reflexividade, tanto pelos indivíduos como pelas coletividades.
} 


\section{NARRATIVAS DOMINANTES SOBRE A IDENTIDADE NACIONAL PORTUGUESA - MITOS DE HOMOGENEIDADE E ESTEREÓTIPOS}

A ditadura, a guerra colonial e a Revolução foram eventos traumáticos ${ }^{12}$, que acabaram por moldar os discursos públicos sobre a identidade nacional, reformulando as memórias coletivas e as fronteiras de grupo internas e externas de uma forma autorreflexiva muito particular. As últimas quatro décadas testemunharam a constante competição na esfera pública portuguesa pela narrativa única e exclusiva, que deveria ser hegemónica. Vários grupos - elites, partidos políticos, académicos - competem em relação à interpretação(ões) da ideologia do Estado Novo e da sua construção discursiva da identidade nacional; além disso, de uma forma aparentemente paradoxal, tanto os partidos de esquerda como os de direita discutem sobre quem entende e narra de forma mais convincente "o passado imaginário", que se mantém fundamental na construção da identidade nacional portuguesa. Este passado tende a voltar ao século XVI, considerado como o momento glorioso da história nacional e coletiva portuguesa, o período histórico que Oliveira Salazar elegera para simbolizar a grande portugalidade.

É de facto notável quão hegemónicos são os mitos constitutivos, especialmente tendo em vista que, como foi referido acima, a máquina da ditadura também reformulou estes momentos históricos para servir a sua agenda política. Seria de esperar a substituição dessas narrativas baseadas nos heróis dos descobrimentos marítimos do século XVI por diferentes heróis como reação à ideologia do Estado Novo.

Nos últimos anos, a identidade nacional portuguesa tem sido uma preocupação de diversas áreas disciplinares, tais como história (Mattoso, 1998), filosofia (Almeida, 2002, 1995; Cruzeiro, 2014; Gil, 2004; Lourenço, 1988, 1997), sociologia (Barreto, 2000, 1995; Conde, 1990; Ribeiro, 2003; Santos, 1993; Sobral, 2004, 2003) e análise de discurso (Ribeiro, 2011), para citar alguns. O problema tem sido debatido tanto em obras literárias como em trabalhos críticos, e têm sido propostas interpretações e leituras sobre o que é a identidade nacional portuguesa e de que forma as memórias coletivas foram e estão a ser formadas'3.

É possível apontar dois argumentos principais em torno da discussão sobre a identidade nacional portuguesa. Por um lado, fundamentada no contexto do século XX, mais especificamente na ditadura salazarista, assistimos à construção discursiva de uma identidade homogénea e unida. Por outro lado, estas alegações são refutadas por investigadores como Mattoso (1998) e Sobral (2003), cujos argumentos são baseados no raciocínio de que a "nação portuguesa foi construída sobre vários elementos desde a Idade Média" (Mattoso, 1998, p. 98). Consequentemente, durante os séculos XIII e $\mathrm{XIV}$, o forte papel nuclear do Estado (e a função de disseminação das representações

\footnotetext{
${ }^{12}$ A vários níveis, a Revolução e a década que se lhe seguiu foram traumáticas para segmentos importantes da população portuguesa. As empresas privadas foram nacionalizadas, a terra agrícola foi tomada pelos trabalhadores rurais, os governos foram de curta duração, a inflação disparou; o estado esteve à beira da falência. Num curto período (1974-1975) o país teve de acolher, abrigar e encontrar emprego para mais de 600 mil pessoas, deslocadas das cinco recém-independentes ex-colónias portuguesas em África.

${ }^{13}$ Ver a este respeito a revista Comunicação e Sociedade, edição especial (volume 29, 2016) dedicada ao tema Imaginários coloniais: propaganda, militância e resistência no cinema.
} 
da nação pela população e elites - aristocracia e clero) foi crucial no processo de reunir vários grupos étnicos sob a ideia de uma nação coletiva.

Anderson (1983/2006, p. 11) data o surgimento da ideia de nação (como uma construção cultural) a partir dos finais do século XVIII (a era do lluminismo e das Revoluções). Esta ideia aparece associada ao nascimento e ascensão da imprensa que possibilitou que as pessoas "observassem réplicas exatas do seu próprio jornal" (Anderson, 1983/2006, p. 35) e, assim sendo, procedessem à construção imaginária da sua comunidade à distância, mas em simultâneo com os outros cidadãos.

Contudo, a originalidade da nação portuguesa encontra-se no facto de que o processo histórico de reunir as pessoas (ou seja, o processo de criação da "comunidade imaginada") sob a égide de uma nação começou muito antes. A ideia de uma unidade cultural portuguesa, juntamente com uma unidade linguística, distingue o país da maioria dos processos europeus de criação da nação, nos quais estes elementos ou não foram tão fortes ou nem sequer coincidem com o estado-nação.

Após extenso investimento crítico das ciências sociais no período pós-revolução - centrado na comparação de Portugal com a Europa em várias vertentes: fenómenos históricos; localização geográfica; distinções entre uma produção económica subdesenvolvida e o recente superdesenvolvido consumo de massas; a significativa lacuna educacional, cultural e económica entre as elites culturais e o restante da população (Cabral, 1992; Santos, 1993) - acredita-se que o país constitui uma unidade sólida, ao mesmo tempo que é reconhecido por aceitar a diversidade devido à sua origem multicultural.

Este último argumento tem alimentado o discurso mais comum ou tradicional sobre a identidade portuguesa, que invoca o caráter excecional do país (Medeiros, 1996, p. 12). Esta singularidade encontra-se tanto na unidade nacional, territorial e linguística do país, como na construção da "comunidade imaginada" que engloba o mito da diversidade nacional. Este mito tem origem no facto histórico de que, até ao século XVI, os portugueses terão sido o produto intrínseco de miscigenação étnica e cultural. Contudo, Barreto (1995, p. 842) afirmou que Portugal é surpreendentemente formado por "um território, um povo, uma nação, uma língua, uma fronteira, uma religião: forjados há séculos, mantidos durante séculos, estas realidades compunham uma unidade rara e permanente na história" (ver também Barreto \& Pontes, 2007).

Num artigo perspicaz, Almeida (2002) divide os contendores do debate sobre identidade nacional em três grupos principais. Identifica o primeiro grupo como sendo os tradicionalistas, que adotam posições essencialistas sem qualquer tipo de rigor científico. O segundo grupo é constituído por cientistas sociais, cuja metodologia é uma combinação de verificação empírica e rigor conceptual com base em dados, estatísticas e abordagens quantitativas. Por fim, o terceiro grupo inclui uma compreensão da história e das humanidades e uma avaliação da "transformação de estruturas subjacentes que unem os elementos de um grupo cultural e a consciência da tradição e a importância simbólica dos fatores formadores de identidade" (Almeida, 2002, p. 6). Não obstante, o autor reforça que "pouquíssimos estudiosos alegam que Portugal possui uma individualidade cultural que o diferencia radicalmente" (Almeida, 2002, p. 9) das outras nações. 
Como Stråth e Wodak (2009, p. 16) salientam, "os conceitos de crise e de mobilização dos valores dicotómicos (certo/errado, sociedade boa/má, amigo / inimigo) [são] refletidos e reforçados na esfera pública através de apelos a valores específicos". Assim, os políticos recorrem ao argumento da "crise de identidade" quando serve a sua agenda política: por exemplo, um programa de rádio com a participação dos ouvintes transmitido em julho de 2006 apresentava o tema "A identidade nacional está em crise?" (ver Ribeiro, 2009). Ou seja, verificamos que o tema foi apresentado e discutido apesar de Lourenço (1988, p. 19) afirmar repetidamente que "Portugal, de ontem e ainda mais de hoje, nunca teve, nem tem, problemas de identidade".

Para concluir esta breve visão geral, ambos os discursos sobre identidade nacional - aquele que reivindica homogeneidade e o que defende uma compreensão excecional da diversidade - são hoje usados pelo poder político dominante para explorar oportunisticamente a relação da nação com a comunidade internacional, conforme discutido abaixo.

\section{IDENTIDADE NACIONAL E O “OUTRO”}

Em geral, os sentimentos nacionalistas surgem nos momentos em que paira um sentimento de ameaça externa. Por um lado, as estratégias discursivas de representação do "outro" são instrumentalizadas para construir um sentido de coesão e de pertença nacional. Por outro lado, a identidade nacional é construída por limites dentro e fora do grupo. Estes limites alteram-se de acordo com o contexto histórico e social de cada instante. As secções abaixo apresentam as principais estratégias de construção do "outro" que ocorreram nas últimas décadas em Portugal.

\section{Portugal e Espanha}

Não é possível mencionar a identidade nacional de Portugal sem a comparar com a de Espanha. A relação entre os dois países tem sido assunto de debate relativo às suas identidades, sejam semelhantes, diferentes ou paralelas (Flynn, 2001; Sobral, 2003). As suas histórias sobrepostas forneceram motivos frutíferos para conflito sobre aspetos mais específicos da definição nacional. Reconhecendo as duas nações como entidades paralelas e complementares, as propostas do século XIX para a construção de uma federação ibérica, por intelectuais portugueses e espanhóis, enfatizavam as identidades aliadas, mas diferentes, dos dois estados-nação (Flynn, 2001, p. 705).

Não obstante este ponto de vista, durante o século XIX e início do século XX, círculos políticos do país vizinho sugeriram recorrentemente que Portugal poderia ser reclamado como parte de Espanha (Flynn, 2001, p. 134). Naturalmente, esta situação mostrava aos portugueses que nem todos os espanhóis reconheciam a legitimidade da soberania portuguesa e da sua identidade nacional específica que, ao contrário da de Espanha, não era contestada pelo crescimento de nacionalismos alternativos. Já no século XX, mesmo dentro de setores semelhantes da direita autoritária espanhola e portuguesa, as opiniões divergiam quanto à relação legítima entre as duas nações, criando uma distância evidente nas relações hispano-portuguesas até o final da década de 1960 . 
Esta desconfiança de Espanha dissipar-se-ia finalmente depois de ambos os países se juntarem à União Europeia em 1986.

\section{Portugal, OS MigRANTES QUE RETORNARAM E OS NOVOS MIGRANTES}

As últimas décadas testemunharam a migração em massa das ex-colónias e das zonas rurais para as áreas urbanas, produzindo deste modo novos discursos de pertença. Após a Revolução de 1974, Portugal recebeu 600.000 "retornados" (cidadãos portugueses das ex-colónias), vendo a sua população crescer em cerca de $5 \%$, num momento da história nacional de séria instabilidade política e de crise económica profunda. Os "retornados" eram na sua maioria emigrantes de segunda ou terceira geração, nascidos no estrangeiro e que nunca haviam pisado terras de Portugal continental'14. Este grupo também incluía angolanos, moçambicanos, cabo-verdianos, etc., com passaporte português, e timorenses (depois da invasão indonésia de Timor-Leste em 1976), que também possuíam passaporte português. Em paralelo, os emigrantes portugueses na Europa ocidental também começaram a voltar para "a sua pátria", a fim de se estabelecerem em definitivo. Por fim, na década de 1990 e no início do século XXI, migrantes económicos, primeiro vindos do Brasil e mais tarde da Europa Oriental (principalmente da Roménia, Moldávia e Ucrânia), chegam em grande número a Portugal (Baganha, Marques \& Góis, 2004). Não obstante, além das referências ao impacto social e económico dos "retornados", estes outros recém-chegados são apenas ocasionalmente referidos por especialistas em estudos sociais, com a notável exceção da pesquisa no campo dos estudos de migrantes e minorias. Da mesma forma, são geralmente omitidos dos discursos presidenciais proferidos no Dia de Portugal's. Poder-se-á, então, afirmar que a construção e a representação da identidade nacional não incluem uma parcela significativa da população.

\section{Portugal e Europa}

O problema das relações de diferença e semelhança entre Portugal e os restantes países europeus (...) permanece tanto mais controverso quanto raramente tem sido objeto de estudo desapaixonado. Deve-se isto, em boa medida, ao facto de Portugal ser um país pequeno e geograficamente estreme, e ao mesmo tempo um velho Estado-nação cuja identidade e interesses se construíram, em parte, por contraste com a Europa continental. (Cabral, 1992, p. 943)

Esta citação resume adequadamente a forma como a construção discursiva da identidade do país tem sido representada. A sua dimensão e localização geográfica dentro da Europa, o facto de ser um estado político duradouro e de "possuir" colónias, são

\footnotetext{
${ }^{14}$ Havia também alguns casos de "retornados" de primeira geração que haviam migrado para a África no início da adolescência ou com vinte e poucos anos.

${ }^{15}$ Ver, a título ilustrativo, os discursos presidenciais proferidos no Dia de Portugal, a 10 de junho, pelos ex-presidentes Jorge Sampaio e Aníbal Cavaco Silva.
} 
um tema recorrente. A partir do século XIX, a independência política de Portugal foi construída e sustentada através das suas possessões territoriais. Sem as colónias, o país sentia que politicamente não seria suficientemente poderoso (ou suficientemente grande) para manter a independência.

Após a Revolução de 1974, Portugal ficou reduzido ao seu território europeu e o debate sobre a identidade nacional foi retomado. Por um lado, o fim da ditadura facilitou a "abertura ao mundo" e o questionamento da identidade nacional nova/antiga; por outro lado, o país teve de se reajustar a uma nova realidade política, na qual a Europa Ocidental se tornara no maior parceiro político e económico. Por conveniência política, depois de 1974, a construção da Europa como o "outro" efetuada tanto por Salazar como pela historiografia, foi rapidamente reformulada como "nós". Simultaneamente, antigas colónias africanas que tinham sido "nós" no Estado Novo, transformam-se num ambivalente "outro" e "nós" no discurso pós-revolucionário, dependendo da agenda estratégica nacional e internacional.

O país tem de resolver a tensão entre as perspetivas política europeia e a luso-tropical. A colonização e a emigração haviam sido componentes da construção da identidade nacional. Historicamente, as elites tinham produzido discursos sobre o significado simbólico das colónias. Os processos recentes, e aliás muito tardios, de democratização, de descolonização e de adesão à União Europeia em 1986, forçam novos discursos e representações do que significa ser português em relação à Europa e ao chamado "desafio europeu".

Aparentemente, as diferenças entre Portugal e a Europa não constituem um problema (Cabral, 1992). De facto, várias sondagens nos anos 90 não destacam diferenças distintas em atitudes, valores e comportamento. A distinção encontra-se antes nos níveis atingidos dentro dos mesmos parâmetros, revelando o atraso das instituições democráticas portuguesas, os processos e a esfera pública fortemente censurada (ver também Gil, 2004).

\section{Conclusão}

É importante relembrar que a construção da identidade (nacional) é um processo fluído. De entre as múltiplas dimensões, a identidade nacional é realizada "como uma distribuição controlada" (ledema \& Caldas-Coulthard, 2008, p. 6). Como resultado, devemos questionar quem tem acesso à implementação da identidade nacional portuguesa, quem controla a sua distribuição, e o quê ou quem é colocado em pano de fundo ou é, por sua vez, omitido. Por exemplo, a reiteração da "comunidade imaginada" como uma sociedade homogénea não abre espaço para a diferença. Da mesma forma, a narrativa hegemónica sobre o "destino do país", "o futuro do país" ou a "abertura do país ao mundo" (em oposição à monitorização cuidadosa da ditadura de qualquer relacionamento entre fronteiras) não abre a esfera pública a narrativas alternativas.

Este ensaio descreve os discursos mais relevantes sobre a identidade nacional portuguesa durante os séculos XIX e XX e quatro argumentos principais foram apresentadas. Primeiro, os historiadores e sociólogos contemporâneos não propõem uma única 
explicação para o que a identidade portuguesa, caráter ou traços, possam ser. Em segundo lugar, baseiam as suas propostas principalmente em processos históricos, embora tenham o cuidado de destacar a complexidade e a variedade múltipla dos fenómenos. Em terceiro lugar, destacam a divisão entre uma minoria de elite - e as respetivas afirmações sobre a essência da portugalidade - e a maioria da população sem instrução e desconhecedora da informação política. Em quarto lugar, o acesso à esfera pública foi seriamente restringido pela ideologia do Estado Novo e pelos seus dispositivos muito específicos para restringir o acesso da população à escola e a inerente ausência de mobilidade social e económica ascendente. Embora por diferentes razões, pode-se afirmar que, até certo ponto, este é ainda o caso. Estas restrições refletem não só a falta de envolvimento da população com o poder político e simbólico, mas também a perceção da desigualdade social e da falta de pluralidade em várias dimensões sociais, (não obstante, e verdade seja dita, estas restrições serem comuns às sociedades neoliberais contemporâneas).

Por conseguinte, e para responder às questões apresentadas no início desta seção sobre quem tem acesso à implementação e definição da identidade nacional portuguesa e quem controla essa distribuição, poder-se-á argumentar que a elite determina os discursos sobre a identidade nacional e de pertença, bem como é quem domina a "sinalização banal da nacionalidade" (Billig, 1995). No entanto, a perceção de Portugal com uma "identidade simbólica forte" (Lourenço, 1997, p. 42) permanece e o que aparentemente prevalece na maioria das narrativas contemporâneas são memórias coletivas recorrentes de eventos históricos, símbolos e escritos literários canónicos.

Em oposição, o ponto de vista étnico-simbólico (Özkirimli, 2000), compartilhado principalmente por filósofos como Almeida (1995, 2002), Gil (2004) e Lourenço (1988, 1997), alega que as elites selecionam elementos com "significado e significância para um grupo em particular", mobilizando pessoas que respondem a pedidos de ação que ecoam através do uso de símbolos e mitos significativos baseados em laços étnicos preexistentes (Skey, 2008, p. 29). No entanto, ao desviar a atenção para a dimensão cultural do nacionalismo, essa perspetiva tende a essencializar a etnicidade, atribuindo "a mitos, símbolos, valores e práticas historicamente significativas um papel importante a desempenhar na criação da imagem da nação" (Skey, 2008, p. 29). Como tal, esta perspetiva não consegue avaliar de que forma estas narrativas de identidade nacional são transformadas ao longo do tempo em resposta aos vários eventos históricos (Skey, 2008, p. 30).

Como vimos, a maior parte das narrativas perpetua a imagem de Portugal como um país muito homogéneo, com uma forte construção discursiva do "nós". De facto, parece até não haver espaço para contradiscursos. Por comparação, enquanto noutros contextos (nacionais) se testemunhou o impacto dos ex-colonizadores, imigrantes e requerentes de asilo na redefinição de uma identidade nacional homogénea, este tipo de influxos não teve qualquer impacto nos discursos sobre a identidade nacional portuguesa (nem na produção académica nem nos discursos mediáticos ou oficiais). Como exemplo recente, em 2015, durante a chamada "crise migratória", a imprensa portuguesa preocupou-se com a representação positiva de Portugal como uma sociedade tolerante, pronta e capaz de participar em ações de apoio e solidariedade aos menos afortunados do que "nós" (Torkington \& Ribeiro, 2018). 
Como a identidade nacional se constrói sobre a memória seletiva e também sobre o esquecimento seletivo, a ausência forçada de factos históricos importantes nas narrativas identitárias para servir propósitos específicos (do estado ou das elites) foi reconhecida há muito tempo, mas isso apenas aumenta a necessidade de criticar essas práticas uma vez que podem envolver várias formas de opacidade.

No entanto, e voltando às palavras de Billig, "se o nacionalismo é uma ideologia mais ampla, cujos lugares-comuns muito familiares nos apanham desprevenidos (...) é ingénuo pensar que um texto de exposição pode escapar ao tempo e lugar da sua formulação" (1995, p. 12), o que significa, naturalmente, que este estudo está inevitavelmente limitado pelo seu próprio contexto de produção.

Tradução: Filipa Perdigão Ribeiro

\section{REFERÊNCIAS}

Ato Colonial 1930, de 8 de julho, República Portuguesa. Retirado de https://www.parlamento.pt/Parlamento/ Documents/acto_colonial.pdf

Almeida, J. C. (2004). Portugal, o Atlântico e a Europa: a identidade nacional, a (re)imaginação da nação e a construção europeia. Nação e Defesa, 107, 147-172. Retirado de http://www.idn.gov.pt/publicacoes/ consulta/NeD/NeDio7/NeDi07.pdf

Almeida, O. T. (1995). Em busca da clarificação do conceito de Identidade Cultural - o caso açoriano como cobaia. Comunicação apresentada nas Actas do Congresso do I Centenário da Autonomia dos Açores, Ponta Delgada.

Almeida, O. T. (2002). National identity - a revisitation of the Portuguese debate. NUI Maynooth papers in Spanish, Portuguese and Latin American Studies. NUI Maynooth.

Almeida, O. T. (2004). Onésimo Teotónio de Almeida: uma entrevista sobre o utopismo português no rescaldo de uma palestra sobre o conceito de identidade. E-topia: Revista Electrónica de Estudos sobre a Utopia, 1, 1-5. Retirado de http://ler.letras.up.pt/uploads/ficheiros/artigo10481.pdf

Anderson, B. (1983/2006). Imagined communities: reflections on the origin and spread of nationalism. Londres e Nova lorque: Verso.

Baganha, M., Marques, J. C. \& Góis, P. (2004). The unforeseen wave: migration from Eastern Europe to Portugal. In M. Baganha \& M. L. Fonseca (Eds.), New waves of migration from Eastern to Southern Europe (pp. 23-40). Lisboa: Metropólis.

Barreto, A. (1994). Portugal, a Europa e a democracia. Análise Social, 29 (129), 1051-1069. Retirado de http:// analisesocial.ics.ul.pt/documentos/1223378256M5dFA4xr9Oe65QI1.pdf

Barreto, A. (1995). Portugal na periferia do centro: mudança social, 1960 a 1995. Análise Social, 30 (134), 841855. Retirado de http://analisesocial.ics.ul.pt/documentos/1223388784X1kPT5fa3Yr88TD2.pdf

Barreto, A. (2000). Portugal e a Europa: quatro décadas. In A situação social em Portugal 1960-1999 (Vol. 2, pp. 37-75). Lisboa: Imprensa de Ciências Sociais.

Barreto, A. \& Pontes, J. (escritores) (2007). 04 Nós e os Outros - Uma Sociedade Plural [TV]. In Rádio Televisão Portuguesa (Produtor), Portugal, um Retrato social, Portugal. 
Billig, M. (1995). Banal nationalism. Londres: Sage.

Biles, J. \& Spoonley, P. (2007). Introduction national identity: what it can tell us about inclusion and exclusion. National Identities, 9 (3), 191-195. DOI: 10.1080/14608940701406146

Braga, T. (1894). A Pátria portuguesa: o território e a raça. Porto: Livraria Chardron.

Braga, T. (1885/1995). O povo português nos seus costumes, crenças e tradições. Lisboa: Publicações Dom Quixote.

Cabral, M. V. (1992). Portugal e a Europa: diferenças e semelhanças. Análise Social, 27 (118-119), 943-954. Retirado de http://analisesocial.ics.ul.pt/documentos/1223055416E2mQD7hfgVw88HW7.pdf

Cabral, M. V. (1999). A sociedade portuguesa e a Revolução de Abril. Comunicação apresentada em Liç̧̃es de História Contemporânea, Universidade do Algarve.

Carvalho, M. \& Cabecinhas, R. (2013). The orthographic (dis)agreement and the Portuguese identity threat. Portuguese Literary Q Cultural Studies, 25, 82-95. Retirado de http://hdl.handle.net/1822/2533525

Castelo, C. (1999). 'O modo português de estar no mundo': o luso-tropicalismo e a ideologia colonial portuguesa: 1933-1961. Porto: Edições Afrontamento.

Castelo, C. (2011). Uma incursão no lusotropicalismo de Gilberto Freyre. Blogue História Lusófona, 6, 261-280.

Conde, I. (1990). Identidade nacional e social dos jovens. Análise Social, 25 (108-109), 675-693. Retirado de http://analisesocial.ics.ul.pt/documentos/1223034770Q7eVC8cc6Clo4LH5.pdf

Correia, A. A. M. (1919). Raça e nacionalidade. Porto: Renascença Portuguesa.

Cruzeiro, M. M. (2014). O 25 de Abril de 1974 memória da revolução e revolução da memória. Revista Lusófona de Estudos Culturais / Lusophone Journal of Cultural Studies, 2, (1), 25-34. Retirado de http:// www.rlec.pt/index.php/rlec/article/viewFile/53/46

Cunha, I. F. (2003). Imagens da imigração em Portugal. Media e Jornalismo, 2, 71-87.

Cunha, I. F. (2004). Imigração e racismo: dez anos nos media. Boca biblioteca on-line da Ciência e Comunicação. Retirado de www.bocc.ubi.pt

Cusack, I. (2005). Tiny transmitters of nationalist and colonial ideology: the postage stamps of Portugal and its Empire. Nations and Nationalism, 11(4), 591-612. DOI: 10.1111/j.1469-8129.2005.00221.x

De Cillia, R., Reisigl, M. \& Wodak, R. (1999). The discursive construction of national identity. Discourse and Society, 10(2), 149-173. DOI: 10.1177/0957926599010002002

Ferreira, J. M. (1993). Portugal em transe (1974-1985). In J. Mattoso (Ed.), História de Portugal (Vol. 8). Lisboa: Círculo de Leitores.

Flynn, M. K. (2001). Constructed identities and Iberia. Ethnic and Racial Studies, 24 (5), 703-718. DOI: $10.1080 / 01419870120063945$

Freyre, G. (1942). Uma cultura ameaçada: a luso-brasileira. Rio de Janeiro: Casa do Estudante do Brasil.

Gellner, E. (1983/2006). Nations and nationalism. Londres: Blackwell Publishing.

Gil, J. (2004). Portugal, hoje: o medo de existir. Lisboa: Relógio D’Água.

Habermas, J. (1962/1991). The structural transformation of the public sphere. Cambridge, Mass.: MIT Press.

Herculano, A. (1846/1980-81). História de Portugal. Lisboa: Livraria Bertrand. 
Iedema, R. \& Caldas-Coulthard, C. R. (2008). Introduction. In R. Idema \& C. R. Caldas-Coulthard (Eds.), Identity trouble: critical discourse and contested identities. Nova lorque: Palgrave, Macmillan.

Lourenço, E. (1988). Identidade e memória. In E. Lourenço (Ed.), Nós e a Europa ou as duas razões (pp. 9-23). Lisboa: Imprensa Nacional - Casa da Moeda.

Lourenço, E. (1997). 1900-2000: Portugal e os desafios finisseculares. In Pavilhão de Portugal Instituto de História Contemporânea, Universidade Nova de Lisboa (Ed.), Portugal na transição do milénio (pp. 3544). Lisboa: Fim de Século.

Lubkemann, S. C. (2002). The moral economy of portuguese postcolonial return. Diaspora: A Journal of Transnational Studies, 11(2), 189-213. Project MUSE, DOI: 10.1353/dsp.2011.0041

Martins, G. de O. (2007). Portugal identidade e diferença. Lisboa: Gradiva.

Martins, J. P. O. (1917 /1879). História de Portugal (Vol. I). Lisboa: Parceria António Maria Pereira.

Mattoso, J. (1998). A identidade nacional. Lisboa: Gradiva.

Medeiros, P. de (1996). Introdução: "Em nome de Portugal". Discursos: Estudos de Língua e Cultura Portuguesa, 13, 12-29.

Mónica, M. F. (1999). Trinta anos que mudaram Portugal. In M. F. Mónica (Ed.), Cenas da vida portuguesa (pp. 13-55). Lisboa: Quetzal.

Özkirimli, U. (2000). Theories of nationalism: a critical introduction. Nova lorque: Palgrave Macmillan.

Passos, S. (2016, 6 de janeiro). "Retornados": os refugiados portugueses do século XX. [Post em blogue]. Retirado de https://euacuso.blogs.sapo.pt/retornados-os-refugiados-portugueses-do-311527

Peixoto, J. (2014). Portugal. In A. Triandafyllidou \& R. Gropas (Eds.), European immigration: a sourcebook (pp. 287-299). Farnham: Ashgate.

Reis, A. (Ed.) (1993). Portugal: 20 anos de democracia. Lisboa: Círculo de Leitores.

Ribeiro, F.P. (2009). The discursive construction of Portuguese national identity: elite vs. lay participants discursive strategies in a phone-in radio show. Papers from LAEL PG 2008, 3, 79-97. Retirado de http:// www.lancaster.ac.uk/fass/events/laelpgconference/papers/v03/Ribeiro.pdf

Ribeiro, F. P. (2011). 'A democratic revolution must always remain unfinished': commemorating the Portuguese 1974 revolution in newspaper opinion texts. Journal of Language and Politics, 10 (3), 372-395. DOI: 10.1075/jlp.10.3.04rib

Ribeiro, M. C. (2003). Uma história de regressos: império, guerra colonial e pós-colonialismo. Oficina do Centro de Estudos Sociais, 188, 1-34.

Rosas, F. (2001). O Salazarismo e o homem novo: ensaio sobre o Estado Novo e a questão do totalitarismo. Análise Social, 35 (157), 1031-1054. Retirado de http://analisesocial.ics.ul.pt/documentos/1218725377D6jF O4wy1Oi67NG6.pdf

Santos, B. S. (1993). Portugal: um retrato singular. Porto: Afrontamento.

Saraiva, A. J. \& Lopes, O. (1987). História da literatura portuguesa. Porto: Porto Editora.

Sidaway, J. D. \& Power, M. (2005). 'The tears of Portugal': empire, identity, 'race', and destiny in Portuguese geopolitical narratives. Environment and Planning D: Society and Space, 23, 527-554. DOI: 10.1068/d345t 
Skey, M. (2008). Flagging nations? Exploring the banality of national discourse through a study of everyday talk and media texts in England. Tese de doutoramento, London School of Economics, Londres, Reino Unido.

Smith, A. D. (1998). Nationalism and modernism: a critical survey of recent theories of nations and nationalism. Londres: Routledge.

Sobral, J. M. (2003). A formação das nações e o nacionalismo: os paradigmas explicativos e o caso português. Análise Social, 37(165), 1093-1126. Retirado de http://analisesocial.ics.ul.pt/documentos/1218 736434JoeQU4wx7Ro77GX9.pdf

Sobral, J. M. (2004). O Norte, o Sul, a raça, a nação - representações da identidade nacional portuguesa (séculos XIX-XX). Análise Social, 39(171), 255-284. Retirado de http://analisesocial.ics.ul.pt/documentos/ 1218705452QonRE7epıTg38ZJ4.pdf

Stråth, B. \& Wodak, R. (2009). Europe - discourse - politics - media - history: constructing 'crisis'? In A. Triandafyllidou, R. Wodak \& M. Krzyzanowski (Eds.), The European public sphere and the media: Europe in crisis (pp. 15-33). Basingstoke, Nova Iorque: Palgrave Macmillan.

Torkington, K. \& Ribeiro, F.P. (2018). 'What are these people: migrants, immigrants, refugees?': migrationrelated terminology and representations in Portuguese digital press headlines. Discourse Context Media. Advance online publication. DOI: 10.1016/j.dcm.2018.03.002

Vieira, R. \& Trindade, J. (2008). Migration, culture and identity in Portugal. Language and Intercultural Communication, 8, 36-49. DOI: 10.2167/laic266.0

Wodak, R. (2006). Discourse-analytic and socio-linguistic approaches to study of nation(alism). In G. Delanty \& K. Kumar (Eds.), The Sage handbook of nations and nationalism (pp. 104-117). Londres: Sage.

\section{NOTA BIOGRÁFICA}

Filipa Perdigão Ribeiro é professora adjunta na Universidade do Algarve, Escola de Gestão, Turismo e Hotelaria (Portugal). Terminou o Doutoramento em Linguística Aplicada pela Universidade de Lancaster (Reino Unido) em 2011. Em 2002, foi convidada para integrar o conselho editorial da revista Dos Algarves: a Multidisciplinay e-Journal, da qual foi co-editora (2006-2016), tendo coeditado uma edição especial dedicada a Línguas, Literatura e Turismo (2014). Os seus interesses atuais de investigação centram-se nas relações entre língua(s), discurso e turismo nas suas múltiplas facetas, identidades nacionais e escrita académica. Publicou artigos sobre identidade nacional Uournal of Language and Politics, 2011), sobre lugar e turistas (International Journal of Culture, Tourism, and Hospitality Research, 2013) e migração (Social Q Cultural Geography, 2017; Discourse, Context Q Media, 2018). Revê regularmente trabalhos submetidos a várias revistas e encontros científicos e é investigadora integrada do CiTUR - Centro de Investigação, Desenvolvimento e Inovação em Turismo (Portugal).

Email: fperdig@ualg.pt

Morada: Universidade do Algarve - ESGHT, Campus da Penha - Estrada da Penha, 8006-139 Faro, Portugal

* Submetido: 17.04.2018

* Aceite: 10.07.2018 